\title{
A COMPARISON WITH THE THREE-ZONE MODEL FOR FLOW BOILING HEAT TRANSFER IN SMALL DIAMETER TUBES
}

\author{
D. Shiferaw, T. G. Karayiannis", D. B. R. Kenning \\ School of Engineering and Design, Brunel University, West London, \\ Uxbridge, Middlesex, UB8 3PH, UK
}

\begin{abstract}
Flow boiling heat transfer experimental results, obtained in two stainless steel tubes of internal diameter $4.26 \mathrm{~mm}$ and $2.01 \mathrm{~mm}$ using R134a as the working fluid, indicate that the local heat transfer coefficient increases with heat flux and is independent of vapour quality when this is less than about $40 \%$ to $50 \%$ for the $4.26 \mathrm{~mm}$ tube and $20 \%$ to $30 \%$ for the $2.01 \mathrm{~mm}$ tube, conventionally interpreted as nucleate boiling. Above these quality values, the separate graphs merge into a single line for heat transfer coefficient decreasing with increasing vapour quality. The data in the apparently-nucleate boiling condition are compared with a recent state-of-the-art three-zone evaporation model for the confined bubble flow regime without a nucleate boiling contribution. The model predicts the experimental data reasonably well but does not predict correctly the trends for changing pressure and diameter. Some suggestions are made for improving the model. The comparisons made in this paper support the statements by the developers of the model and others that the application of conventional macro flow boiling correlations to micro tube flow boiling heat transfer may not necessarily have a sound physical basis.
\end{abstract}

Keywords: Flow boiling, flow pattern, heat transfer, two-phase flow, elongated bubble, small diameter

*Corresponding Author: tassos.karayiannis@brunel.ac.uk

\section{Nomenclature}

$C_{\delta 0} \quad$ correcting factor on the initial

film thickness (dimensionless)

Co confinement number (dimensionless)

$d \quad$ diameter, $(m)$

$G \quad \operatorname{mass}$ flux $\left(\mathrm{kg} / \mathrm{m}^{2} \mathrm{~s}\right)$

$q$ heat flux $\left(\mathrm{W} / \mathrm{m}^{2}\right)$

$U \quad$ velocity $(\mathrm{m} / \mathrm{s})$

$z \quad$ axial distance $(m)$

GREEK SYMBOLS

$\tau \quad$ pair period $(s)$

$\begin{array}{ll}\text { SUBSCRIPTS } \\ \text { crit } & \text { Critical } \\ \text { dry } & \text { dryout of liquid film } \\ \text { end } & \text { end of the liquid film } \\ \text { film } & \text { liquid film between bubble and wall } \\ \text { min } & \text { Minimum } \\ \text { p } & \text { pair (liquid slug/bubble) } \\ \text { ref } & \text { Reference } \\ \text { sat } & \text { Saturation } \\ 0 & \text { Initial }\end{array}$

\section{Introduction}

Advances in materials technology have allowed the extended use of micro-electro-mechanical systems. However, the understanding of the transport phenomena in these systems and their thermal modelling is still a subject of intense research effort by the international community. A number of research teams studying flow boiling heat transfer in small diameter tubes and microchannels 
reported a better heat transfer performance for small diameter tubes compared with the conventional diameter tubes, e.g. Palm (2003), Agostini and Bontemps (2004), Huo et al. (2006). Experimental results for small diameter tubes also demonstrated that the heat transfer coefficient more or less independent of vapour quality and mass flux, while it is strongly dependent on heat flux and saturation pressure, Lazarek and Black (1982), Wambsganss et al. (1993), Bao et al. (2000). Conventionally, this is interpreted as evidence that nucleate boiling is the dominant heat transfer mechanism. However, using macroscale boiling heat transfer correlations and models based on the above premise and developed from the macroscale models to predict the heat transfer coefficient in small diameters resulted in under prediction of the data of Owhaib and Palm (2003) and Huo et al. (2006). Furthermore, a number of experimental studies have shown some effect of mass velocity and vapour quality on heat transfer, e.g. Reid et al. (1987), Carey et al. (1992), Tran et al. (1996), Yan and Lin (1998). Based on experience of boiling in large tubes, they concluded that forced convection dominates in the vapour quality range where dependence of the heat transfer coefficient on quality is observed.

The mechanism of heat transfer in small tubes is influenced by the surface tension forces. A commonly used threshold criterion where macroscale heat transfer modelling becomes unreliable for predicting flow boiling heat transfer coefficients was defined by Kew and Cornwell (1997) as a function of the confinement number, which depends on the surface tension and the densities of the liquid and vapour and thus on the system pressure, $C o=\left[\sigma /\left(g\left(\rho_{l}-\rho_{g}\right)\right]^{1 / 2} / d\right.$. As the diameter decreases or the Co number increases above the threshold given by this criterion, i.e. 0.5 , bubble growth is confined by the channel to the point where individual bubbles grow in length rather than in diameter. This is variously termed the elongated bubble regime, confined bubble flow or (following macro channel terminology) slug flow. Recent flow visualization experiments by Chen et al. (2005) with R134a for a pressure range of 6-14 bar indicated that reducing the tube diameter from $4.26 \mathrm{~mm}$ to $1.1 \mathrm{~mm}$ affected the flow pattern transition boundaries. The confined bubble flow appeared at 6 bar in the $2.01 \mathrm{~mm}$ and at all pressures in the $1.10 \mathrm{~mm}$ tube. These observations were in approximate agreement with the threshold diameters predicted by the confinement number criterion, which ranged from $1.7 \mathrm{~mm}$ at 6 bar to $1.4 \mathrm{~mm}$ at 14 bar system pressure.

There have been many studies of fluctuations in the pressure difference between the inlet and outlet plena of small-diameter channels in adiabatic and boiling flows in the confined bubble regime. There have been only a few studies in which local measurements of the fluctuations in pressure and wall temperature were synchronized with visual studies of the bubble motion, necessarily confined to channels of rectangular cross-section. Yan and Kenning (1998) investigated water boiling in a $2 \mathrm{x}$ $1 \mathrm{~mm}$ channel. They showed that the pressure fluctuations were caused by the acceleration of liquid slugs by expanding confined bubbles, confirming a model of Kew and Cornwell (1996), and that the corresponding fluctuations in saturation temperature were of similar magnitude to the mean superheat causing evaporation, so they could not be neglected. The fluctuations were accompanied by cyclic changes in the local mechanism of heat transfer between single and two-phase convection and nucleate boiling that did not fit the conventional interpretations of time-averaged heat transfer coefficients, Kenning and Yan (2001), Wen et al. (2004). Brutin and Tadrist (2004) made similar local observations for n-pentane boiling in a $4 \mathrm{x} 1 \mathrm{~mm}$ channel and observed that the average heat transfer coefficient reached its peak value in the fluctuation regime. Lin et al. (2001) reported that the wall temperature fluctuated significantly at higher heat flux values and this was caused by a combination of time varying heat transfer coefficient and time varying local pressure and fluid saturation pressure. Zhang et al. $(2004,2005)$ showed that the fluctuations in pressure, saturation temperature and wall temperature became more extreme for water boiling in micro-channels with cross-sectional dimensions below $0.17 \mathrm{~mm}$, so that they might influence mechanical integrity as well as thermal performance. Current models and correlations for flow boiling in microchannels do not take fluctuations in saturation temperature into account. 
Zhang et al. $(2004,2005)$ also noted that the highest heat transfer in their microchannels was achieved in confined bubble flow at sufficiently low time-averaged exit quality to avoid dryout of the liquid film round the bubbles. Wen et al. (2002) observed at very low mass fluxes the downstream propagation of transient high wall temperatures indicative of dryout, even at low heat fluxes. In channels of circular cross-section, in which events in the boiling region cannot be observed directly, decreases in time averaged heat transfer coefficient with increasing quality, often accompanied by fluctuating wall temperatures, have been attributed to transient dryout, particularly at low mass flux, Huo et al. (2006). Microchannel heat transfer correlations models generally do not make allowance for partial dry out.

This paper compares, the experimental results obtained with two stainless steel tubes of internal diameter $4.26 \mathrm{~mm}$ and $2.01 \mathrm{~mm}$ using R134a at 8 bar and 12 bar system pressure, with the threezone evaporation model for confined bubble flow proposed by Thome et al. (2004) which includes a mechanism of periodic dryout. The main characteristics of the model, which contains three empirically determined constants, are described briefly in Section 2.

\section{Brief Review of the Model}

A brief review is given below of the three-zone model developed by Thome and co-workers. The full details are given in Thome et al. (2004) and Dupont et al. (2004). They proposed this flow boiling heat transfer model, which predicts the local dynamic and the local time-averaged heat transfer coefficient at fixed locations along the channel based on the evaporation of elongated bubbles. This was developed from an earlier two-zone heat transfer model, Jacobi and Thome (2002). As shown in Figure 1, following the passage of a liquid slug, a bubble is modelled to pass as a confined elongated bubble trapping a thin liquid film against the inner wall. If the liquid film does dry out before the arrival of the next liquid slug then a vapour slug follows (triplet). If not, then the model assumes the existence of a pair consisting of the liquid slug and the elongated bubble. Therefore, one of the novelties of the model is the fact that it considers a dryout zone and exploits the transient evaporation of the film. The model does not include a contribution from nucleate boiling.

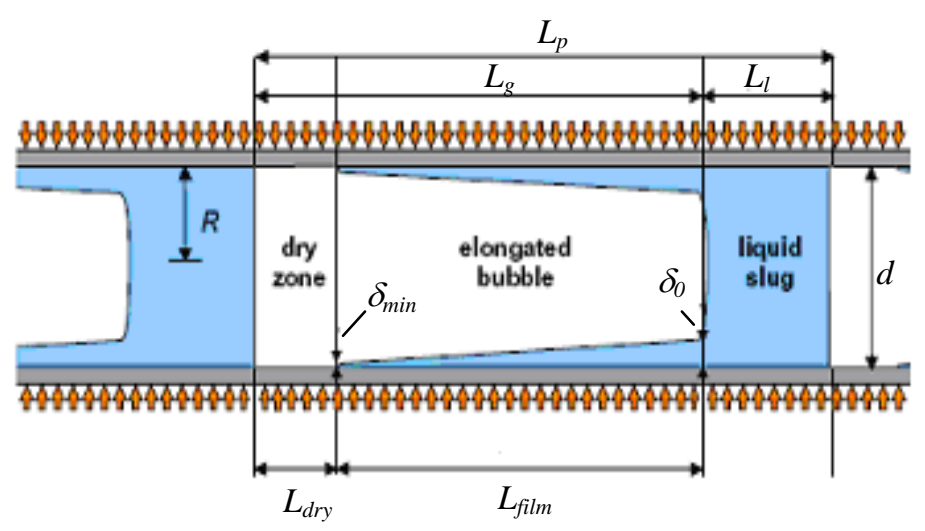

Figure 1: Diagram illustrating the three zones: a liquid slug, an elongated bubble and a vapour slug, Thome et al. (2004).

The model determines the time-averaged local heat transfer coefficient as,

$$
h(z)=\frac{t_{l}}{\tau} h_{l}(z)+\frac{t_{f i l m}}{\tau} h_{f i l m}(z)+\frac{t_{d r y}}{\tau} h_{v}(z)
$$

where, 


$$
\begin{gathered}
t_{l}=\frac{\tau}{1+\frac{\rho_{l}}{\rho_{v}} \frac{x}{1-x}} \quad t_{g}=\frac{\tau}{1+\frac{\rho_{v}}{\rho_{l}} \frac{1-x}{x}} \quad t_{d r y} f i l m \\
f=\frac{1}{\tau}
\end{gathered}
$$

The time periods used in the model are as follows: $t_{l}$ corresponds to the time it takes for the liquid slug to pass a fixed location $\mathrm{z}$ through the cross section; $t_{\text {film }}$ is the residence time of the film; $t_{d r y}$ represents the duration of the local wall dryout; $t_{g}$ corresponds to the presence of vapour (dryout and film zone) passing location $\mathrm{z}$; $t_{d r y}$ film is the maximum duration of the existence of the film at position $\mathrm{z}$ till dryout occurs at the minimum feasible film thickness $\left(\delta_{\min }\right)$. According to Thome et al. (2004), if $t_{d r y}$ film $<t_{g}$, local dryout occurs, i.e. the liquid film thickness reaches the minimum feasible film thickness, $\delta_{\text {end }}(z)=\delta_{\text {min }}$, and $t_{\text {film }}=t_{d r y}$ film. This implies that $t_{d r y}=t_{g}-t_{f i l m}$. On the other hand, if $t_{d r y}$ film $>t_{g}$, then no dryout occurs since the next liquid slug arrives before dryout of the film occurs and, $\delta_{\text {end }}(z)=\delta\left(z, t_{g}\right)$, In this case, $t_{\text {film }}=t_{g}$.

In equation (1) above, $h_{l}(z)$ and $h_{v}(z)$ are heat transfer coefficients of the liquid and vapour slugs. They are calculated from their local Nusselt numbers using the respective equivalent lengths of the liquid slug, $\mathrm{L}_{\mathrm{l}}$ and dry wall zone $\mathrm{L}_{\mathrm{dry}}$, see Figure 1 . Thome et al. (2004) cited and recommended the London and Shah correlation for laminar developing flow and the Gnielinski correlation for transition and turbulent developing flow. The Churchill and Usagi (1972) asymptotic method was used to obtain a continuous expression of the mean heat transfer coefficient as a function of Reynolds number.

The mean heat transfer coefficient through the evaporating thin liquid film surrounding the elongated bubble, $h_{\text {film }}(z)$, was obtained as follows assuming one-dimensional heat conduction in a stagnant thin liquid film:

$$
\begin{gathered}
h_{\text {film }}(z)=\frac{k_{1}}{\delta_{0}-\delta_{\text {end }}} \ln \left(\frac{\delta_{0}}{\delta_{\text {end }}}\right) \\
\delta(z, t)=\delta_{0}(z)-\frac{q}{\rho_{l} h_{\mathrm{lg}}} t \\
\frac{\delta_{0}}{d}=C_{\delta_{0}}\left(3 \sqrt{\frac{v_{l}}{U_{p} d}}\right)^{0.84}\left[\left(0.07 B o^{0.41}\right)^{-8}+0.1^{-8}\right]^{-1 / 8} \\
U_{p}=G_{\text {tot }}\left[\frac{x}{\rho_{v}}+\frac{1-x}{\rho_{l}}\right] \\
B o=\frac{\rho_{l} d}{\sigma} U_{p}^{2}
\end{gathered}
$$

The researchers did not define analytically three parameters, which needed to be optimised empirically using an experimental database namely: the minimum thickness of the liquid film at dryout $\left(\delta_{\min }\right)$, the pair frequency $(f)$, equation (2), which is the frequency of the bubble generation and the correction factor, $C_{\delta 0}$. They determined the initial thickness of the liquid film using the Moriyama and Inoue (1996) film thickness prediction and applied an empirical correction factor, $C_{\delta 0}$ as shown in equation (5). In the presentation of the model (Thome et al. 2004), the film thickness was governed by the evaporation of the liquid film. However, in Dupont et al. (2004), where they compared the model predictions with a database (1591 test data for R11, R12, R113, $\mathrm{R} 123, \mathrm{R} 134 \mathrm{a}, \mathrm{R} 141 \mathrm{~b}$ and $\mathrm{CO}_{2}$ ), they used a constant average film thickness. They also 
recommended general values of the parameters after optimising empirically each parameter with the whole range of the database.

$$
\begin{gathered}
\delta_{\text {min }}=0.3 \mu \mathrm{m} \\
f_{\text {opt }}=\left(\frac{q}{q_{\text {ref }}}\right)^{1.74} \mathrm{~Hz}
\end{gathered}
$$

The reference heat flux $\left(q_{\text {ref }}\right)$ was given as a function of the reduced pressure based on the method employed by Cooper (1984) for the pool boiling correlation,

$$
q_{\text {ref }}=3328\left(\frac{P_{\text {sat }}}{P_{\text {crit }}}\right)^{-0.5}
$$

The constant values of $3328 \mathrm{~W} / \mathrm{m}^{2}$ as well as the values of the exponents of equation (9) and (10), i.e. 1.74 and -0.5 , respectively were obtained from the complete experimental database (which included R134a). The constant in equation (5) was again obtained using the database as:

$$
C_{\delta 0}=0.29
$$

In this paper, the above recommended general values, equation (8) - (11), were adopted in calculating the local and average heat transfer coefficients that were used to compare with the results of the current experiments.

\section{Experimental Results}

An R134a experimental facility was designed and used for these experiments. A detailed description and a schematic are available in Huo et al. (2006). The test sections were made of stainless steel cold drawn tubes; the first one was $4.26 \mathrm{~mm}$ in internal diameter, roughness $1.75 \mu \mathrm{m}$ with $0.245 \mathrm{~mm}$ wall thickness and $500 \mathrm{~mm}$ in length; the second test tube was $2.01 \mathrm{~mm}$ in internal diameter, roughness $1.82 \mu \mathrm{m}$ with $0.19 \mathrm{~mm}$ wall thickness and $211 \mathrm{~mm}$ in length. In the heat transfer experiments, the fluid entered the test section in a subcooled state and was evaporated to a quality of about $90 \%$ or less in most cases, depending on the mass flux and the heat flux. Direct electric heating was applied to the test section. Fifteen K-type thermocouples were soldered to the outside of the tube at equal distances to provide the wall temperatures. The first and last thermocouple readings were not used in the analysis so as to avoid conduction errors. T-type thermocouples and pressure transducers were used to measure inlet and outlet temperatures and pressures. An energy balance based on the electrical heat supplied minus losses and the enthalpy change enabled the exit quality to be calculated. The total enthalpy change across the test section was calculated based on the flow rate of the refrigerant and the pressure and temperature change measured by the differential pressure transducer and thermocouple, respectively, at two ends of the test section. All the instruments used were carefully calibrated. The uncertainty in temperature measurement was $\pm 0.2 \mathrm{~K}$, flow rate measurements $\pm 0.4 \%$, and pressure measurements $\pm 0.15 \%$. The average error in the heat transfer coefficient was $\pm 6 \%$. A series of flow boiling tests were performed at different mass flux and heat flux. The result of the flow visualization part of this study is presented in detail in Chen et al. (2004). The local flow boiling heat transfer coefficients for R134a were obtained for the range: pressure 8 and 12 bar, heat flux $13-150 \mathrm{~kW} / \mathrm{m}^{2}$, mass flux 100 $500 \mathrm{~kg} / \mathrm{m}^{2} \mathrm{~s}$, vapour quality $0-0.9$ and tube diameter 2.01 and $4.26 \mathrm{~mm}$. Further details on the data processing including the calculation of the, local heat transfer coefficient at are available in Huo et al. (2006).

The experimental local heat transfer coefficient is plotted as a function of quality in Figure 2 for the 4.26 and $2.01 \mathrm{~mm}$ tubes. The figure shows some of the typical results at a mass flux of $300 \mathrm{~kg} / \mathrm{m}^{2} \mathrm{~s}$. The complete set of experimental data used in this paper for the range specified above is available in Huo (2006). As seen in the figure, at low values of heat flux, when $x<0.5$ for the $4.26 \mathrm{~mm}$ and $\mathrm{x}$ $<0.3$ for the $2.01 \mathrm{~mm}$ tube, the heat transfer coefficient depends on the heat flux and is almost independent of quality, within experimental uncertainty. Based on experience of boiling in large 
tubes, this is conventionally interpreted as evidence that nucleate boiling is the dominant heat transfer mechanism. However, Thome et al. (2004) argued that for small passages, the same behaviour can be explained if transient evaporation of the thin liquid film surrounding elongated bubbles is the dominant heat transfer mechanism, not nucleate boiling.

At vapour quality greater than $40 \%-50 \%$ for the $4.26 \mathrm{~mm}$ tube and $20 \%-30 \%$ for the $2.01 \mathrm{~mm}$ tube, the heat transfer coefficient becomes independent of heat flux and is strongly dependent on quality. In the smaller tube, at the highest heat flux $\mathrm{q}=123 \mathrm{~kW} / \mathrm{m}^{2}$, the heat transfer coefficient decreases monotonically from $\mathrm{x}=0$. In the region of decreasing heat transfer coefficient, the tube wall temperature was observed to be highly unstable leading to high transient temperatures and the experiment was stopped in from time to time to avoid damaging the test section. Therefore, for the range mentioned above (i.e. vapour quality greater than $40 \%-50 \%$ for the $4.26 \mathrm{~mm}$ tube and $20 \%$ $30 \%$ for the $2.01 \mathrm{~mm}$ tube), the decrease in heat transfer coefficient with increasing vapour quality may be due to partial dryout, Huo et al. (2006).

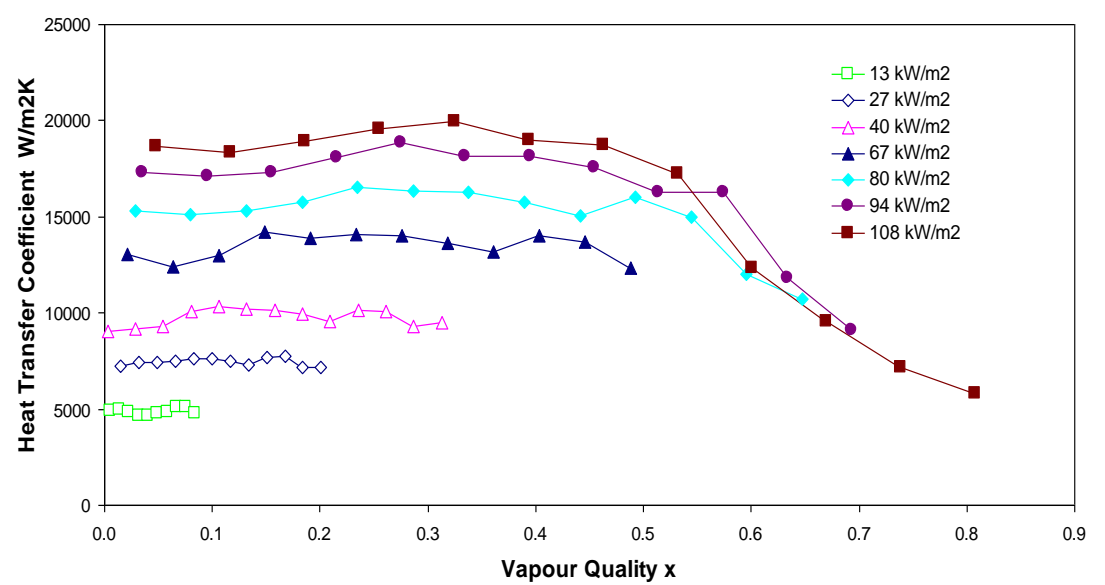

(a)

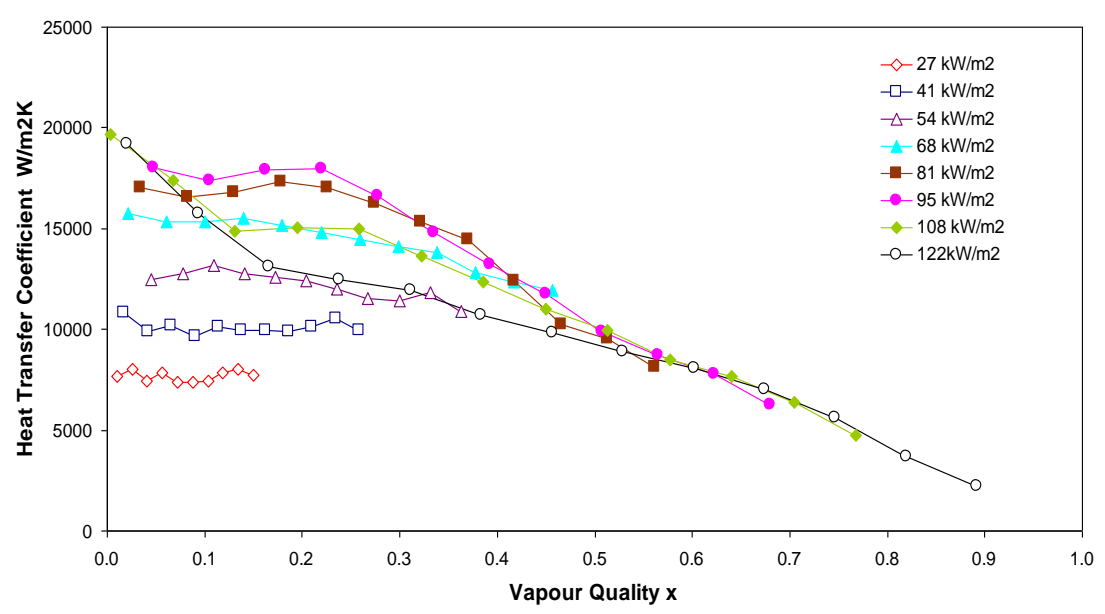

(b)

Figure 2: Local heat transfer coefficient as a function of vapour quality with various heat flux; $G=$ $300 \mathrm{~kg} / \mathrm{m}^{2} \mathrm{~s}, \mathrm{P}=8$ bar: (a) $\mathrm{d}=4.26 \mathrm{~mm}$, (b) $\mathrm{d}=2.01 \mathrm{~mm}$, Huo et al. (2006).

\section{Comparison with the Three-Zone Evaporation Model and Discussion}

Figures below present the comparison with the three-zone model of Thome et al. (2004) described in brief above. The comparison is made with the complete set of the experimental data range specified above. However, the high heat flux data, specifically for vapour quality greater than $50 \%$ for the $4.26 \mathrm{~mm}$ tube and $30 \%$ for the $2.01 \mathrm{~mm}$ tube, included for example in Figure 2 were rated 
unstable and unrepeatable. These ranges will be re-examined in the current research, which will also include smaller diameter tubes. For the purpose of comparison they are not included at this stage. Figure 3 depicts the local heat transfer coefficient predicted by the model as a function of the corresponding experimental value for all mass flux $\left(100-500 \mathrm{~kg} / \mathrm{m}^{2} \mathrm{~s}\right)$ at a pressure 8 and 12 bar. The model consistently over-predicts the $4.26 \mathrm{~mm}$ data by 20 to $40 \%$ at a pressure of 8 bar, Figure 3a. At a pressure of 12 bar, in Figure $3 b$, good agreement is achieved, i.e. within $\pm 15 \%$; there is a tendency to over-predict at higher values of the heat transfer coefficient. For the $2.01 \mathrm{~mm}$ tube, the data are predicted within $\pm 20 \%$ at 8 bar (Figure 3c) and are mostly under-predicted up to $30 \%$ at 12 bar (Figure 3d). The data are more scattered for the $2.01 \mathrm{~mm}$ tube than for the larger $4.26 \mathrm{~mm}$ tube. This reasonably satisfactory global performance supports the proposition that a model that excludes nucleate boiling can nevertheless represent the "apparently nucleate boiling regime" but the bias in the predictions with changing tube diameter and system pressure suggests that the performance of the model should be examined more closely.

Figure 3a, includes a group of data points that are greatly under-estimated by the model. They are all associated with very low vapour qualities $(\mathrm{x} \cong 0$ to 0.13$)$ i.e. near the inlet to the test section. This serious disagreement may be attributable to the onset of nucleate boiling, i.e. exclusion of bubble formation in the unconfined bubbly flow region in the model. The model assumes all-liquid flow up to the inception of the confined bubbles at $\mathrm{x}=0$ and employs a laminar fully developed single-phase heat transfer correlation that gives heat transfer coefficients much lower than that of unconfined bubbly flow region. The examples in Thome et al. (2004) always have a heat transfer coefficient that changes from a very low value at $\mathrm{x}=0$ to a large value at a small positive value of $\mathrm{x}$, followed by a slight decrease with further increase in $\mathrm{x}$, as seen in the following comparisons of the axial development of the experimental and predicted coefficients. These points at very low $\mathrm{x}$ have been omitted from the other plots in Figure 3 as unrepresentative of developed confined bubble flow. Figure 3 also shows that the predicted heat transfer coefficient values are less for the smaller diameter than for the larger diameter unlike the corresponding experimental values.

The local heat transfer coefficient versus vapour quality is depicted in Figure 4 for the tube with internal diameter $2.01 \mathrm{~mm}$ at both pressures. The experimental values are always high at $\mathrm{x}=0$, remain at approximately the same level, with some fluctuations that are mostly within the bounds of experimental uncertainty. An excellent agreement with the experimental values at a system pressure of 8 bar is clear, especially at relatively low heat and mass flux up to $G=400 \mathrm{~kg} / \mathrm{m}^{2} \mathrm{~s}$ and $\mathrm{q}=68$ $\mathrm{kW} / \mathrm{m}^{2}$. 


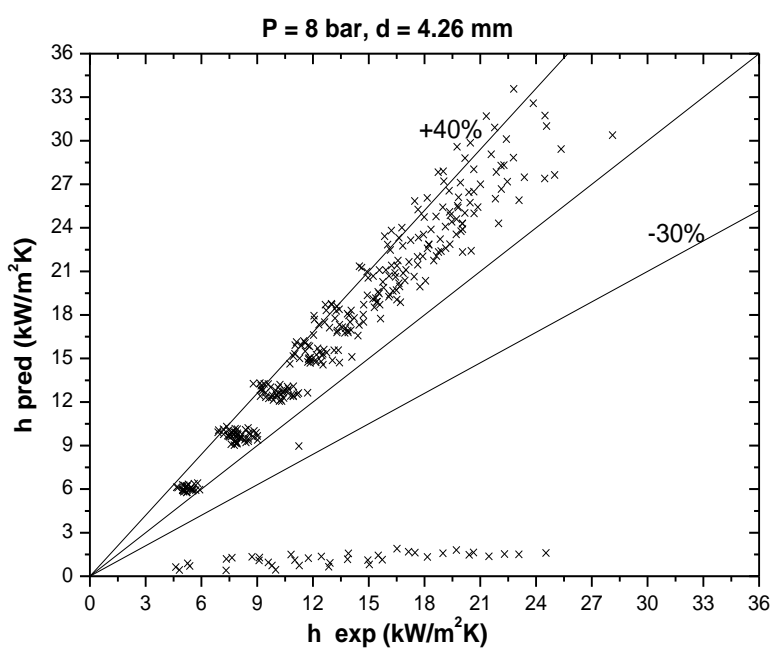

(a)

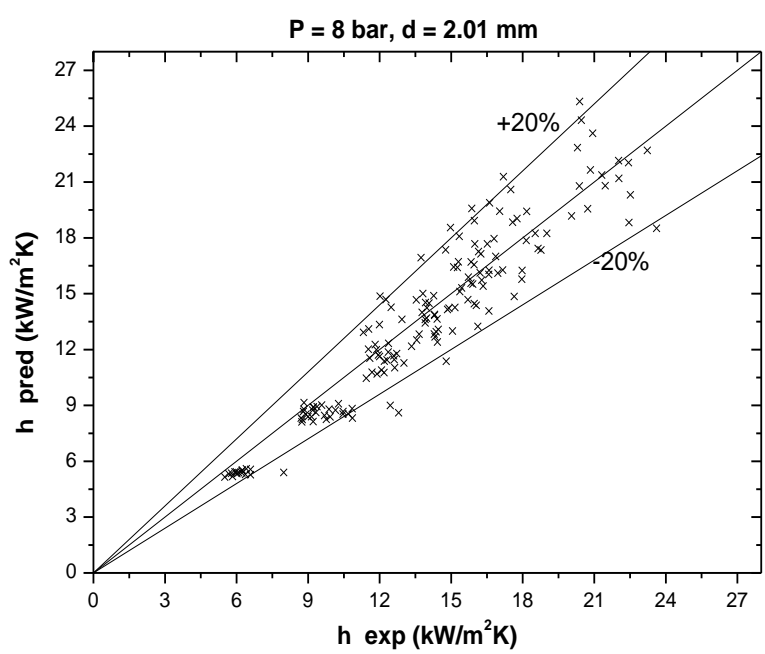

(c)

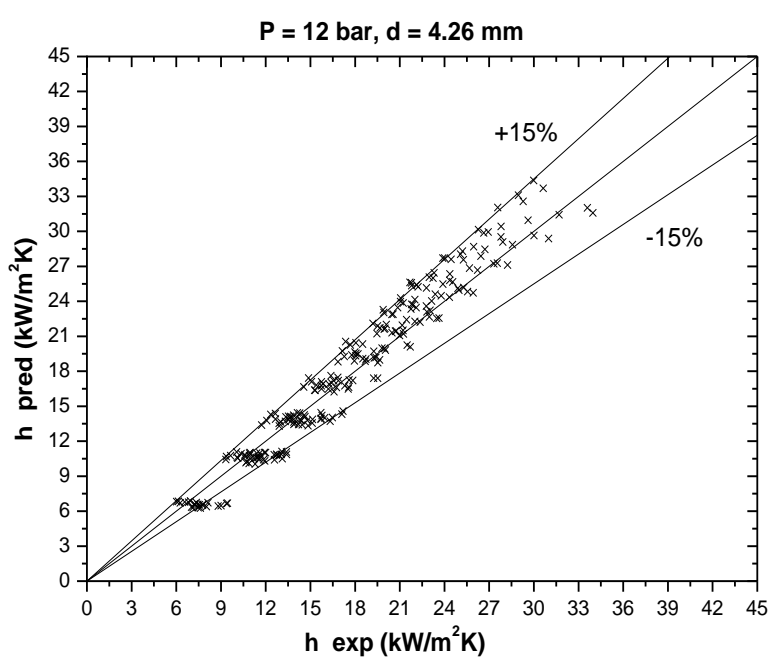

(b)

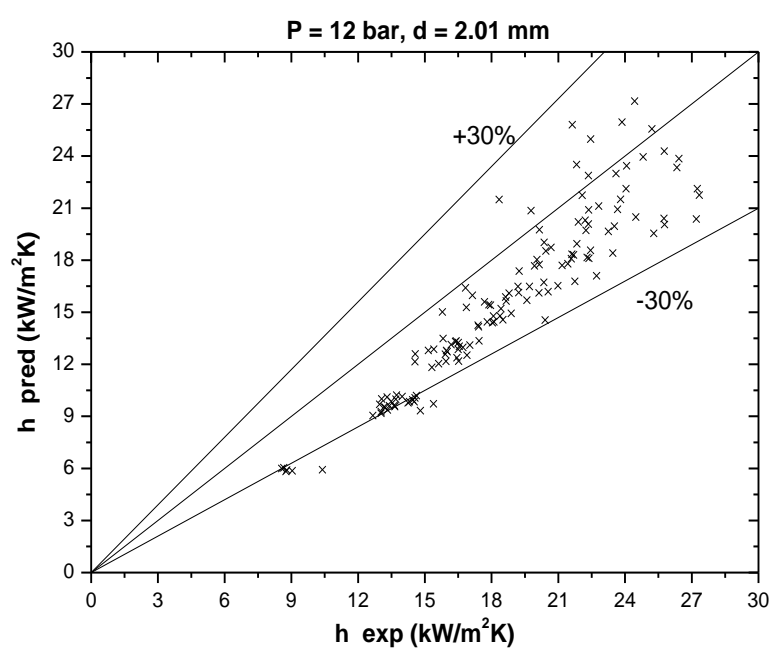

(d)

Figure 3: Comparison between the local heat transfer coefficient predicted by the Thome et al. (2004) model and the corresponding experimental values: (a) $d=4.26 \mathrm{~mm}, \mathrm{P}=8$ bar, (b) $\mathrm{d}=4.26$ $\mathrm{mm}, \mathrm{P}=12$ bar, (c) $\mathrm{d}=2.01 \mathrm{~mm}, \mathrm{P}=8$ bar, (d) $\mathrm{d}=2.01 \mathrm{~mm}, \mathrm{P}=8$ bar.

Figure $4 \mathrm{~b}$ presents the same comparison for the same diameter but at a system pressure of 12 bar. As seen in the figure, the experimental data are under predicted at lower mass and heat flux $(\mathrm{G} \leq$ $300 \mathrm{~kg} / \mathrm{m}^{2} \mathrm{~s}, \mathrm{q} \leq 45 \mathrm{~kW} / \mathrm{m}^{2}$ ). At high values the predication is much better. Again as stated above, the predicted heat transfer coefficient tends to decrease slightly with vapour quality after a peak at around $\mathrm{x} \sim 0.05$ for the entire range. The experiment results remain nearly constant.

A comparison with the model of local heat transfer coefficient versus vapour quality for the larger diameter $(4.26 \mathrm{~mm})$ is presented in Figure $5 \mathrm{a}$ and $\mathrm{b}$ at a system pressure of 8 and 12 bar respectively. As seen in Figure 5a, the model over-predicts the data for the entire range, with the difference increasing with increasing heat flux. A decrease in the predicted local heat transfer coefficient with vapour quality is seen, especially at high heat flux. 


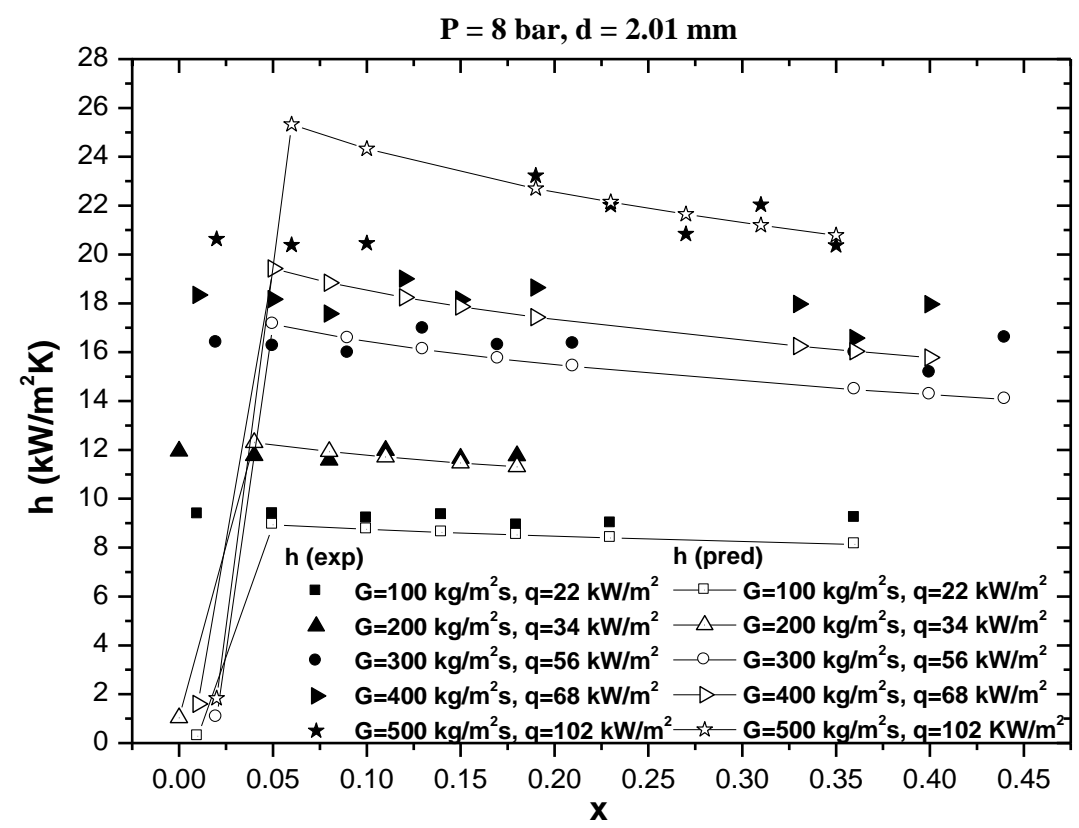

(a)

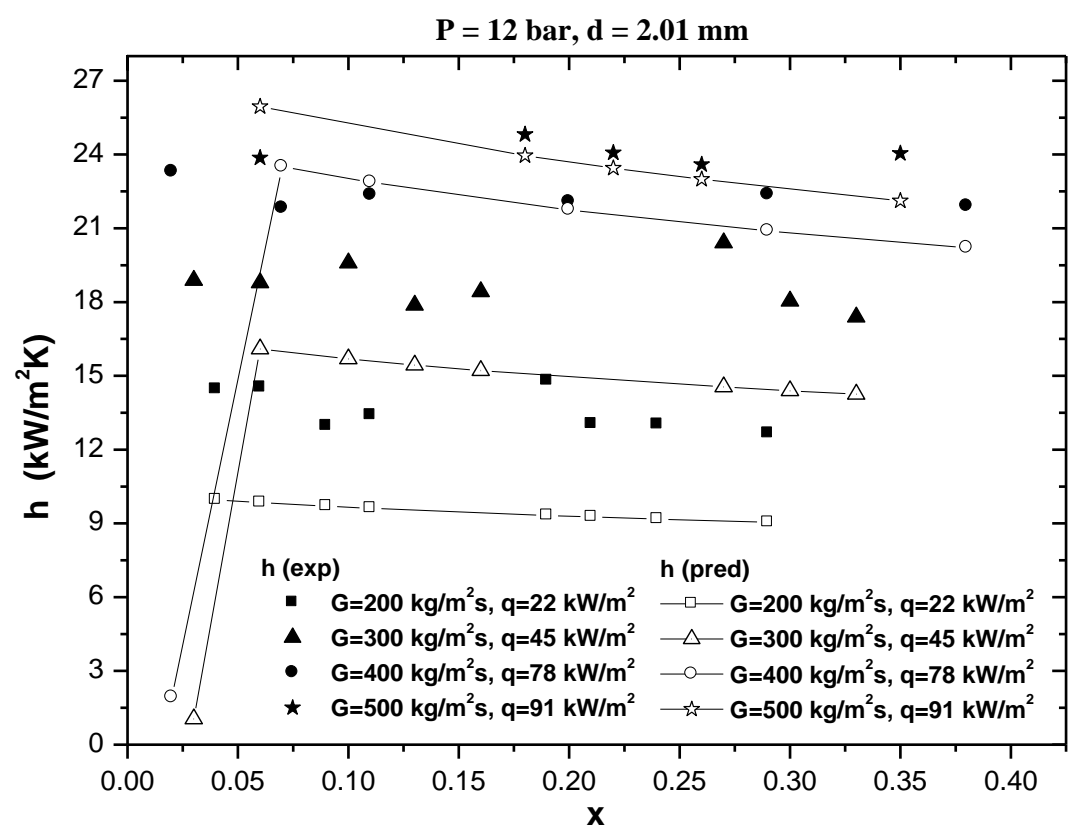

(b)

Figure 4: Comparison of the Local heat transfer coefficient versus vapour quality with Thome et al. (2004) model for $\mathrm{d}=2.01 \mathrm{~mm}$ : (a) $\mathrm{P}=8 \mathrm{bar}$, (b) $\mathrm{P}=12$ bar.

In Figure 5b, at 12 bar, the larger diameter experimental results are predicted well for $\mathrm{q} \leq 60 \mathrm{~kW} / \mathrm{m}^{2}$ and $\mathrm{G} \leq 300 \mathrm{~kg} / \mathrm{m}^{2} \mathrm{~s}$. At higher values of heat and mass flux the model over-predicts the experiment results. In general, the model predicts the larger diameter tube data better for the 12 rather than the 8 bar system pressure.

It has been shown that the global performance of the model varies with system pressure. This is illustrated in Figure $6 \mathrm{a}$ and $\mathrm{b}$ for the two different diameter tubes. Figure $6 \mathrm{a}$, for the $2.01 \mathrm{~mm}$, shows that the local heat transfer coefficient increases with pressure at various heat and mass flux values. 


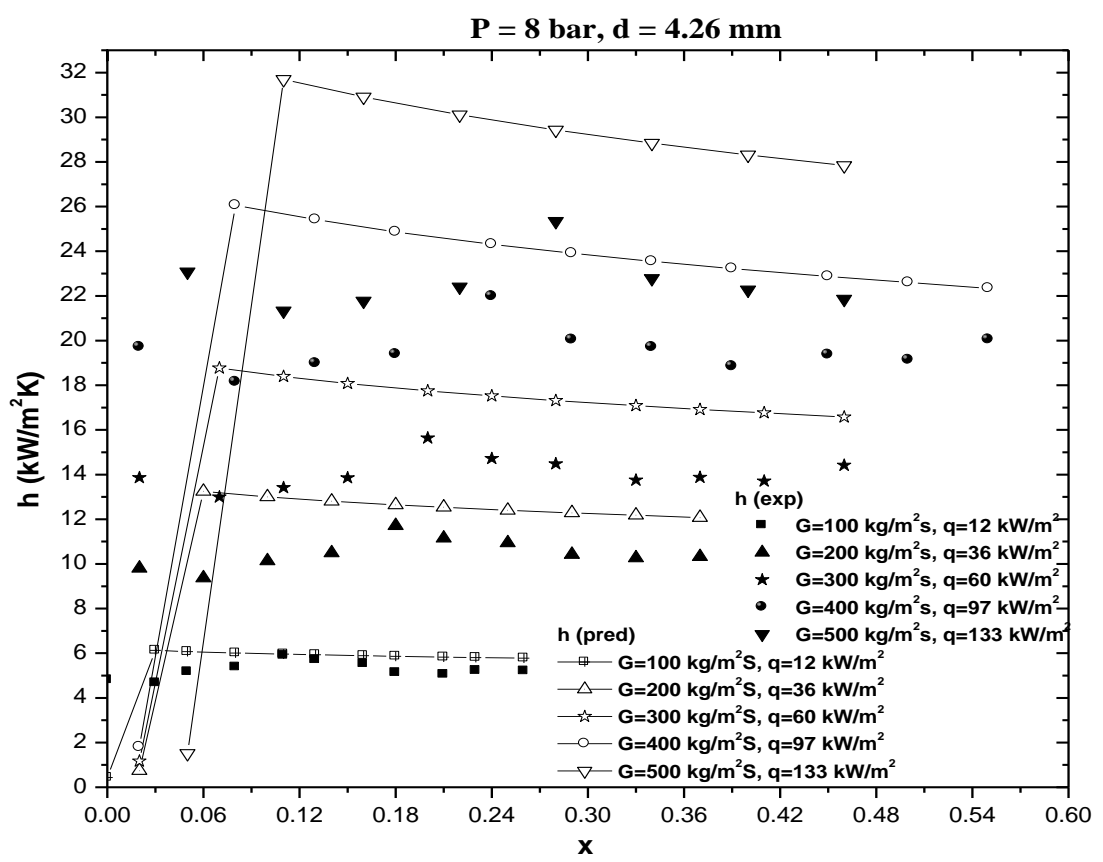

(a)

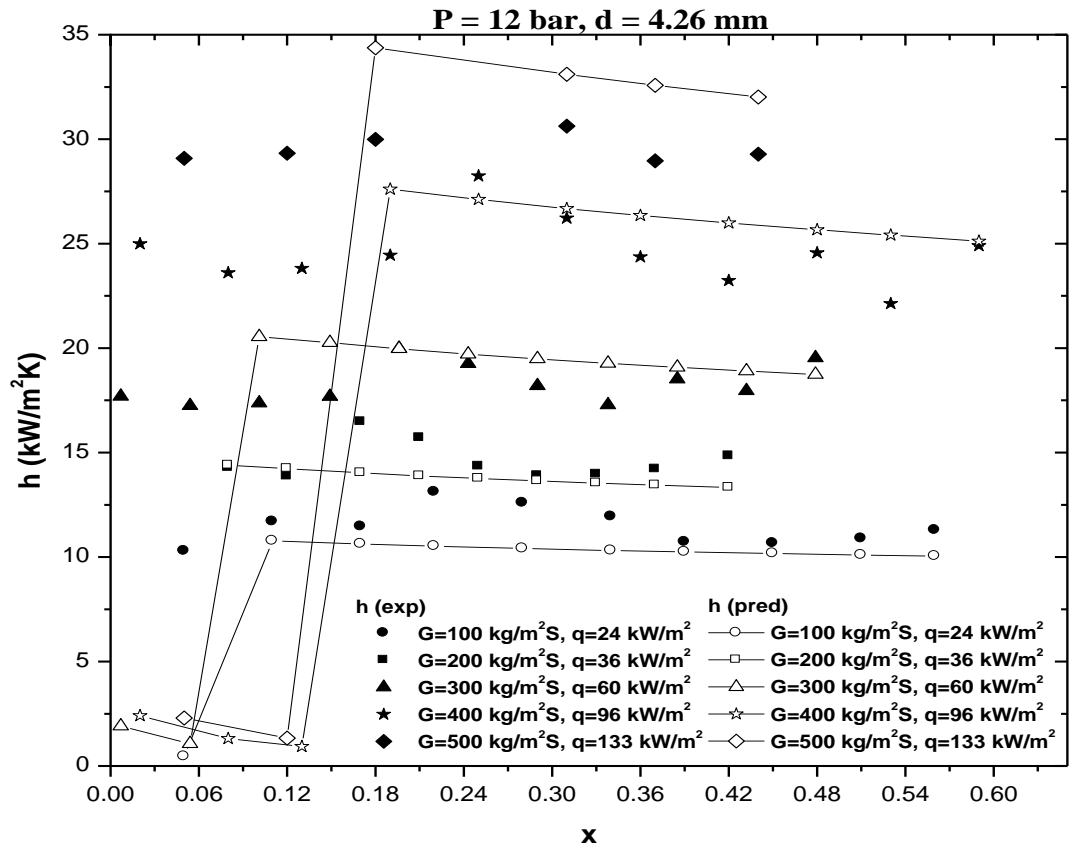

(b)

Figure 5: Comparison of the Local heat transfer coefficient versus vapour quality with Thome et al (2004) model for $\mathrm{d}=4.26 \mathrm{~mm}$ : (a) $\mathrm{P}=8$ bar, (b) $\mathrm{P}=12$ bar

However, the model does not predict the same degree of change. For example, when the system pressure changes from 8 to 12 bar, the experimental local heat transfer coefficient increases by approximately 25 to $35 \%$, unlike the predicted local heat transfer coefficient, which shows an average increase of only $12 \%$. The corresponding values, in Figure $6 \mathrm{~b}$, for the $4.26 \mathrm{~mm}$, are approximately 30 to $40 \%$ and again $12 \%$. 


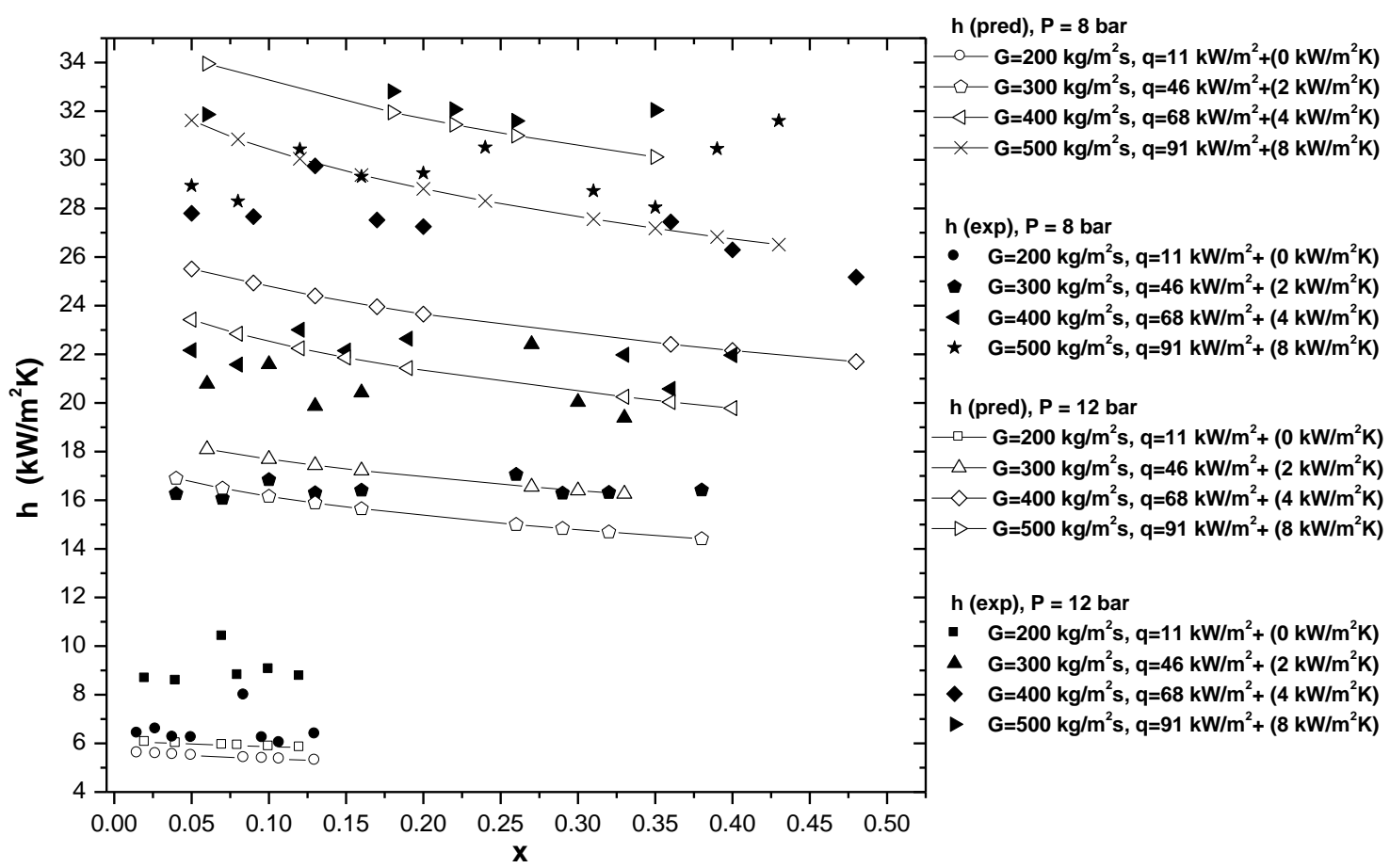

(a)

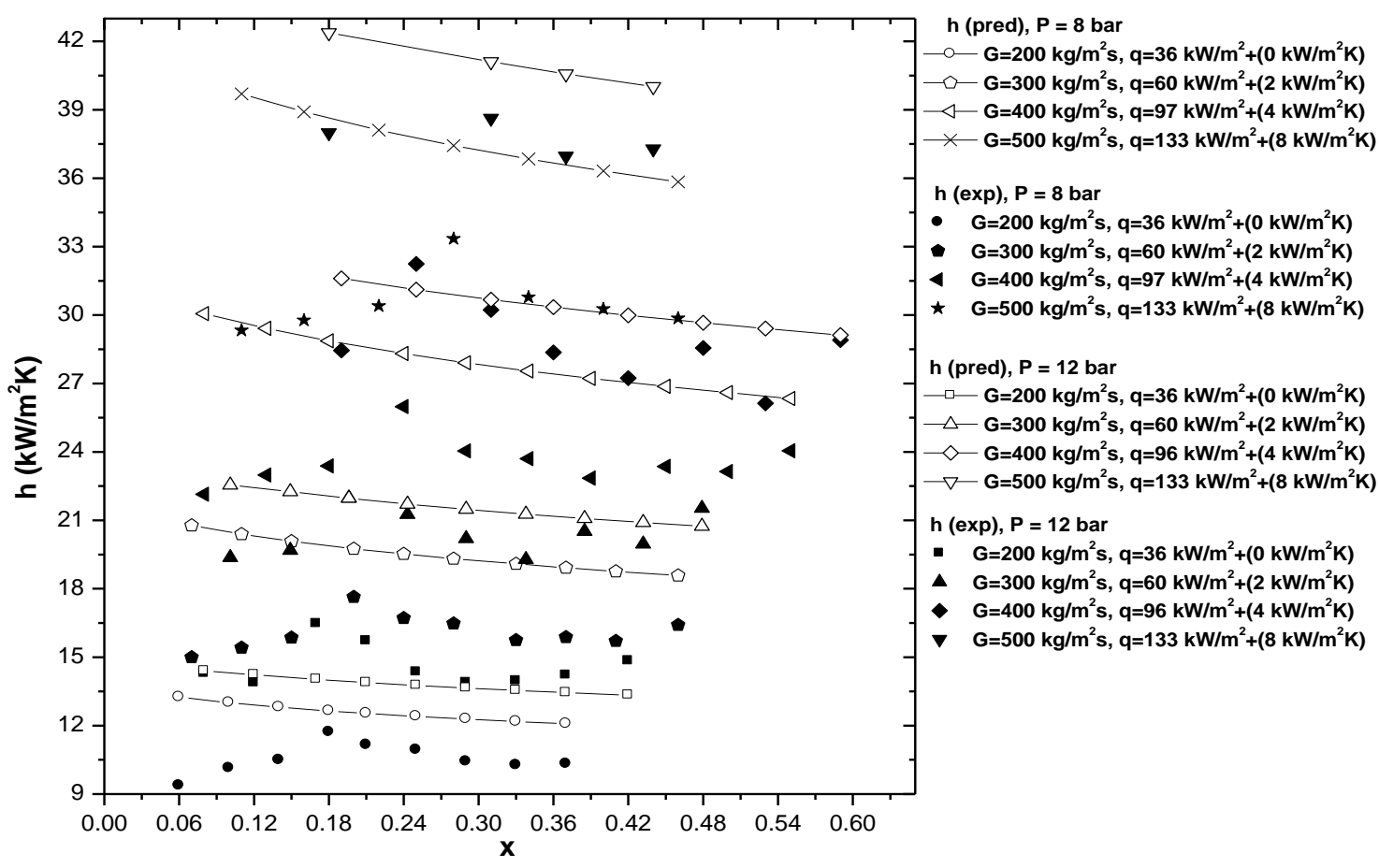

(b)

Figure 6: Comparing the predicted local heat transfer coefficient versus vapour quality for the two pressures: (a) $\mathrm{d}=2.01 \mathrm{~mm}$, (b) $\mathrm{d}=4.26 \mathrm{~mm}$.

Based on the comparison above, features of the model that may require modification include the analytical determination of the bubble generation frequency, and the initial and end film thicknesses. The modifications of Moriyama and Inoue (1996) film thickness correlation for the prediction of the initial film thickness by Thome et al. (2004) have eliminated the influence of bubble growth time. This modification results in an entirely different prediction of the behaviour for the condition of increasing bubble velocity in a tube of fixed radius, i.e. that the film thickness reaches maximum value and then decreases, which appears to be inconsistent with the available 
experimental evidence for steady flow. Also, the model assumes already formed elongated bubbles and does not include the inception of the elongated bubbles and their growth from departing bubbles, i.e. the initiation of the confined bubble regime at $x=0$ needs to be revised. The model is unusual in that it does include a mechanism of periodic dryout but does not take account of the fluctuations in saturation temperature. This is a simplification, which may or may not be valid in all circumstances, which must be examined elsewhere. Assessment of such variations may require a major extension of the model if shown to be significant. Discrepancy in the pressure effect could be attributed to a limitation of the one-dimensional model, which does not solve the equation of motion for the liquid slug to allow the variation in pressure. On the other hand, the high pressure gives higher vapour density that leads to lower vapour superficial velocity. As a result, pressure changes could cause a flow map shift, (i.e. a shift from elongated bubble regime) which affects the model applicability. However, the model does not accommodate such variations. The model may also need to consider cyclic occurrence of nucleate boiling in thin film regions, as observed by Kenning and Yan (2001), Wen et al. (2004). It is clear from the above that further work is needed in this area.

\section{Conclusions}

The experiment results for the $4.26 \mathrm{~mm}$ tube demonstrate that the heat transfer coefficient increases with heat flux and system pressure, but does not change with vapour quality when the quality was less than about $40 \%$ to $50 \%$. For the $2.01 \mathrm{~mm}$ tube, this boundary moves to $20 \%-30 \%$ vapour quality. This is conventionally interpreted as evidence that nucleate boiling is the dominant heat transfer mechanism in this vapour quality range. For vapour quality values greater than $40 \%-50 \%$ for the $4.26 \mathrm{~mm}$ tube and $20 \%-30 \%$ for the $2.01 \mathrm{~mm}$ tube, the heat transfer coefficient does not depend on heat flux and decreases with vapour quality. This could be caused by partial dryout.

A detailed comparison of the present results with the state-of-the-art, three-zone evaporation model of Thome et al. (2004) was presented in this paper. The model is based on convective heat transfer in the confined bubble regime, without any contribution from nucleate boiling. It predicts fairly well experimental data that conventionally would be interpreted as nucleate boiling. This shows that a model without a nucleate boiling contribution may provide a reasonably successful approximate prediction of "apparently nucleate boiling" heat transfer regime. The model has capability to predict influence of dryout but this has not been tested in this paper. The model predicts that the diameter of the tube has opposite effect on the heat transfer coefficient as that indicated by the actual data. The trend in the heat transfer coefficient with pressure changes is correctly predicted but the actual change is greater than that given by the model. Features of the model that may require modification are discussed and pointed out in the previous section.

\section{References}

Agostini, B. and Bontemps, A, 2004, Vertical flow boiling of refrigerant R134a in small channels, Int. Journal of Heat and Fluid Flow, In Press.

Bao, Z. Y., Fletcher, D. F. and Haynes, B. S., 2000, Flow boiling heat transfer of Freon R11 and HCFC123 in narrow passages, Int. Journal of Heat and Mass Transfer, Vol. 43, pp. 3347-3358.

Brutin, D. Tadrist, L., 2004, Pressure drop and heat transfer analysis of flow boiling in a microchannel: influence of the inlet condition on two-phase flow stability, Int. J. Heat Mass Transfer, Vol. 47, pp. 2365-2377.

Carey, V. P., Tervo, P. and Shullenberger, K., 1992, Partial dryout in enhanced evaporator tubes and its impact on heat transfer performance, SAE Technical Paper 920551.

Chen, L., Tian, Y.S. and Karayiannis, T.G., 2005, R134a Flow patterns in small-diameter tubes, J. Process Mechanical Engineering, Vol. 219, pp 167-181.

Chen, L., Tian, Y.S. and Karayiannis, T.G., 2006, The effect of tube diameter on vertical two-phase flow regimes in small tubes, Submitted, Int. Journal Heat and Mass Transfer. 
Churchill, S.W. and Usagi, R., 1972, A general expression for the correlation of rates of transfer and other phenomena, AIChE J. 18, pp. 1121-1128.

Cooper, M.G., (1984), Heat flow rate in saturated nucleate pool boiling--a wide-ranging examination using reduced properties, Advances in Heat Transfer, Vol. 16, Academic Press, Orlando, pp. 157-239.

Dupont, V., Thome, J. R., Jacobi, A.M., 2004, Heat transfer model for evaporation in microchannels., Part II: comparison with the database, Int. J. Heat and Mass Transfer, Vol. 47, pp. 3387-3401.

Huo, X., 2006, Experimental study of boiling heat transfer in small diameter tubes, $\mathrm{PhD}$ thesis, London South Bank University, London, UK

Huo, X., Tian, Y.S. and Karayiannis, T.G., 2006, R134a flow boiling heat transfer in small diameter tubes, In press, International Journal of Heat Exchangers.

Kenning, D.B.R. and Yan, Y., 2001, Saturated flow boiling of water in a narrow channel: experimental investigation of local phenomena, IChemE Trans. A, Chem. Eng. Res. and Design 79, 425-426.

Kew, P.A., Cornwell, K., 1996, On pressure fluctuations during boiling in narrow channels, $2^{\text {nd }}$ European Thermal-Science and $14^{\text {th }}$ UIT National Heat Transfer Conference, Rome2, 1323-1327.

Kew, P. and Cornwell, K., 1997, Correlations for the prediction of boiling heat transfer in small diameter channels, Applied Thermal Engineering Vol. 17, No. 8-10, pp. 705-715.

Lazarek, G. M. and Black, S. H., 1982, Evaporative heat transfer, pressure drop and critical heat flux in a small vertical tube with R-113, Int. J. Heat Mass Transfer, Vol. 25, No. 7, pp. 945-960.

Lin, S., Kew, P.A., and Cornwell, K., 2001, Two-phase heat transfer to a refrigerant in a $1 \mathrm{~mm}$ diameter tube, Int. J. Refrigeration, Vol. 24, pp 51-56.

Moriyama, K. and Inoue, A., 1996, Thickness of the liquid film formed by a growing bubble in a narrow gap between two horizontal plates, J. Heat Transfer, Vol. 118, pp 132-139.

Owhaib, W. and Palm, B., 2003, Flow boiling heat transfer in vertical circular microchannel tube, Eurotherm seminar no. 72, Valencia, Spain, 31 March-2 April.

Palm, B., 2003, Mini-and microchannel research in Sweden, Proceedings of $1^{\text {st }}$ ASME internaltional conference in microchannels and minichannels, Rochester, New York, pp 25-31

Thome, J. R., Dupont, V., Jacobi, A.M., 2004, Heat transfer model for evaporation in microchannels., Part I: presentation of the model, Int. J. Heat and Mass Transfer, Vol. 47, pp. 33753385 .

Tran, T. N., Wambsganss M. W. and France D. M., 1996, Small circular- and rectangular-channel boiling with two refrigerants, Int. J. Multiphase Flow, Vol. 22, No. 3, pp. 485-498.

Wambsganss, M. W., France, D. M., Jendraejczyk, J. A. and Tran, T. N., 1993, Boiling heat transfer in a horizontal small-diameter tube, Journal of Heat Transfer, Vol. 115, pp. 963-972.

Wen, D.S., Kenning, D.B.R. and Yan, Y., 2002, Flow boiling of water in a narrow vertical channel at low mass flux: observations of local phenomena, Proc. $12^{\text {th }}$ International Heat Transfer Conference, Grenoble, vol. 3, pp. 773-778

Wen, D.S., Yan, Y. and Kenning, D.B.R. (2004) Saturated flow boiling of water in a narrow channel: time-averaged heat transfer coefficients and correlations, Applied Thermal Engineering 24,1207-1223

Yan, Y. Y. and Lin, T. F., 1998, Evaporation heat transfer and pressure drop of refrigerant R-134a in a small pipe, Int. J. Heat Mass Transfer, Vol. 41, pp. 4183-41.

Yan, Y. and Kenning, D.B.R., 1998, Pressure and temperature fluctuations during boiling in narrow channel, Eurotherm 62: Heat Transfer in Condensation and Evaporation, Grenoble, pp. 107-1223.

Zhang, L., Goodson, K.E. and Kenny, T.W., 2004, Silicon microchannel heat sinks, theories and phenomena, chap. 5-7, Springer, Berlin.

Zhang, L., Wang, E.N., Goodson, K.E. and Kenny, T.W., 2005, Phase change phenomena in silicon microchannels, Int. J. Heat Mass Transfer, Vol. 48, pp. 157 2-1582. 